\title{
Diagnoses of chronic beryllium disease within cohorts of sarcoidosis patients
}

\author{
J. Müller-Quernheim*, K.I. Gaede*,\#, E. Fireman` and G. Zissel*
}

\begin{abstract}
An increase in chronic beryllium disease (CBD) has been suggested due to higher industrial use of beryllium alloys. Since occupational CBD is a perfect phenocopy of sarcoidosis, it might be misdiagnosed as sarcoidosis. In the current it was hypothesised that CBD exists in cohorts of sarcoidosis patients.
\end{abstract}

In a prospective case study, sarcoidosis patients were evaluated for potential beryllium exposure. In those patients in whom beryllium exposure was confirmed and beryllium hypersensitivity demonstrated, the diagnosis of sarcoidosis was rejected and corrected to CBD.

In 84 patients seen for re-evaluation or making a diagnosis of sarcoidosis, beryllium exposure was recognised and a diagnosis of CBD was made in 34 out of 84 patients. The time lag between clinical diagnosis of sarcoidosis and the final diagnosis of CBD ranged 0-18 yrs (median 3 yrs) and the mean (range) age at time of diagnosis of CBD was 43.9(25-80) yrs. Berylliumcontaminated workplaces causing disease encompassed a wide spectrum of industries and technical trades in which beryllium-exposure is generally not perceived as a health hazard.

In conclusion, chronic beryllium disease still belongs to the spectrum of differential diagnoses of granulomatous disorders.

KEYWORDS: Chronic beryllium disease, diagnosis, lymphocyte proliferation test, sarcoidosis

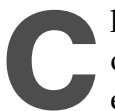
hronic beryllium disease (CBD) is an occupational hypersensitivity disorder elicited by beryllium exposure in the workplace. It is characterised by noncaseating granuloma within affected organs, predominantly lung and skin [1]. Due to their attractive properties, copper, aluminium, nickel, magnesium and iron alloys containing beryllium are increasingly used in various industries and trades [2, 3]. Historically, the defence, nuclear and aerospace sectors have been the largest users of beryllium-containing alloys. Meanwhile, however, $>50 \%$ of the annual beryllium consumption of the USA, which is 200 metric tons, is distributed to the computer and electronic industries [4]. A similar percentage can be assumed for other industrialised nations. As a consequence of the increasing use of beryllium, it is estimated that the number of exposed workers in the USA has risen from 30,000 in the 1970 s to 200,000 or even 800,000 in 2000. Moreover, 4,000-16,000 undiagnosed cases of CBD may exist in the USA alone [5]. In this context, it is remarkable that CBD is only rarely diagnosed. Since it is a perfect phenocopy of sarcoidosis, its differential diagnosis relies on occupational history giving evidence for beryllium exposure and tests demonstrating beryllium sensitisation [6, 7]. For the latter, routine tests are only available at a few specialised centres, which leads to the assumption that unrecognised CBD arising outside the classical beryllium worker populations may be misdiagnosed as sarcoidosis [4, 8, 9]. In the past, several groups, including the present authors' group, reported on the diagnosis of CBD made in the diagnostic work-up of "sarcoidosis patients" [8-10]. Therefore, the current authors included CBD in the differential diagnostic spectrum that is routinely checked when making the diagnosis of sarcoidosis.

Thus, a detailed occupational history was obtained from all patients in one tertiary referral centre in Germany and one in Israel where sarcoidosis was either diagnosed for the first time or re-evaluated. In addition, the berylliumlymphocyte proliferation test (BeLPT) was established in the present authors' institutions for routine use. Based on published data, the current authors asked for workplaces and work processes known to be associated with beryllium-containing dusts, fumes, aerosols or vapours and for potential bystander exposure [2, 4, 11]. In cases with potential exposure, BeLPT was performed with peripheral blood mononuclear cells to check for beryllium sensitisation [12]. After making the medical diagnosis of CBD based on positive BeLPT results and clinically assumed beryllium
AFFILIATIONS

*Dept of Pneumology, Medical

University Hospital Freiburg,

Freiburg, and

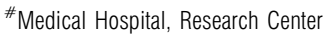

Borstel, Borstel, Germany.

-Dept of Pulmonary and Allergic

Diseases, Tel Aviv Sourasky Medical

Center, Tel Aviv, Israel.

CORRESPONDENCE

J. Müller-Quernheim

Dept of Pneumology

University Medical Center

Medical University Hospital Freiburg

5 Killianstraße

Freiburg 79106

Germany

Fax: 4976612703704

E-mail: jmq@medizin.ukl.uni-

freiburg.de

Received:

September 272005

Accepted after revision:

February 242006

SUPPORT STATEMENT

This work was supported in part by a grant of the Deutsche

Forschungsgemeinschaft Bonn,

Germany (Mu 692/7-1).

European Respiratory Journal

Print ISSN 0903-1936

Online ISSN 1399-3003 
exposure, a definitive diagnosis was established by an occupational evaluation of the workplace. Here, the current authors report their experience on the differential diagnosis of $\mathrm{CBD}$ in a nonoccupational, routine setting of apparent sarcoidosis in internal medicine clinics.

\section{MATERIALS AND METHODS Patient selection}

From October 1997 to May 2005, patients with obvious or suspected occupational beryllium exposure referred for the clinical work-up of suspected sarcoidosis or CBD entered the study at the Medical Hospital, Research Centre Borstel (Borstel, Germany; from 1997 to 2001), the Dept of Pneumology, University Medical Centre, Albert Ludwigs University (Freiburg, Germany; from 2002 to 2005), and the Dept of Pulmonary and Allergic Diseases, Sourasky Medical Center (Tel Aviv, Israel; 1998 to 2005). To identify patients with possible beryllium exposure, a list of workplaces with exposure risk was compiled and updated on the basis of the current literature $[2,11]$. A detailed occupational history was taken from every sarcoidosis patient admitted to the centres using this list. Demographic details and the contribution of the centres in Germany and Israel are shown in table 1. The occupational settings in which the current authors identified CBD cases are given in table 2. In addition, the following potential contacts during production or maintenance processes were inquired about when taking the occupational case history: microwave devices, transistor mountings, wheels, high-end sport devices (racing bicycles, golf clubs, etc.), satellites and electronic military guidance systems. However, none of the patients worked with an exposure risk in these additional settings. This approach resulted in a prospective case collection of 84 "sarcoidosis patients" with possible or known beryllium exposure. Exposure was verified by consultation of the respective occupational medicine service and if necessary by a site visit through the respective legal authority.

\section{Control populations}

In total, 76 healthy employees of the involved institutions donated blood for BeLPT after an uneventful, routine occupational medicine examination including occupational history questions which specifically examined circumstances with potential beryllium exposure. In addition, 31 sarcoidosis patients without corticosteroid treatment and no known beryllium exposure served as controls to demonstrate the specificity of the BeLPT (table 1). In addition, 13 healthy colleagues of the patients with an identical exposure pattern gave a blood sample for BeLPT (table 1).

\section{BeLPT}

All patients and controls in the current study were free of systemic corticosteroid medication for $\geqslant 6$ months prior to testing. A sample of venous blood was collected and mononuclear cells were prepared by gradient centrifugation. The BeLPT was initiated within $6 \mathrm{~h}$ of veinpuncture following established protocols [12-14] fulfilling the technical specifications of the United States Dept of Energy published in 2001 (Specification 1142-2001 Department of Commerce, Technology Administration, National Technical Information Service, Springfield, VA, USA). Briefly, mononuclear cells were cultured at a density of $0.5 \times 10^{6}$ cells $\cdot \mathrm{mL}^{-1}$ either without any in vitro stimulus (background and negative control; 32fold), with $5 \mu \mathrm{g}$ phytohaemagglutinin per $\mathrm{mL}, 10 \mu \mathrm{g}$ Concanavalin A (positive controls; eight-fold, respectively), or with $\mathrm{BeSO}_{4}$ in concentrations ranging $10^{-5}-10^{-10} \mathrm{~mol} \cdot \mathrm{L}^{-1}$ (eight-fold each). After 3 days of culture ${ }^{3} \mathrm{H}$-thymidine, or bromo-desoxyuridine was added to measure cell proliferation using established methods [12, 13, 15]. Both approaches are equivalent to that recently suggested by FROME et al. [16] including reference tests from healthy individuals.

\section{Diagnostic criteria of CBD}

To establish the diagnosis of CBD, the following criteria were used as previously suggested [1]: 1) symptomatic disease with histological demonstration of noncaseating granuloma, pulmonary function impairment, and abnormal chest radiographs otherwise diagnosed as sarcoidosis; 2) proof of beryllium sensitisation by two independently positive BeLPTs in the absence of any treatment with systemic corticosteroids for $\geqslant 3$ months; and 3) proof of beryllium exposure. For the latter, occupational safety experts of the relevant occupational health authorities evaluated the workplace.

In those cases which fulfilled criteria two and three, but without criterion one, beryllium sensitisation was diagnosed $[1,17]$.

TABLE 1 Results of beryllium-lymphocyte proliferation test (BeLPT) in beryllium-exposed and -unexposed individuals

\begin{tabular}{|c|c|c|c|c|c|}
\hline & Subjects n & Exposure & BeLPT $^{\#}$ & Age yrs & Female/male \\
\hline CBD & $34(22 / 12)$ & + & + & $43.9 \pm 13.2$ & $11 / 23$ \\
\hline Healthy & $76(70 / 6)$ & - & - & $41.9 \pm 16.1$ & $37 / 39$ \\
\hline Sarcoidosis & $31(29 / 2)$ & - & - & $45.9 \pm 11.8$ & $19 / 12$ \\
\hline \multicolumn{6}{|c|}{ Beryllium-exposed groups without CBD } \\
\hline Sarcoidosis & $50(35 / 15)$ & + & - & $46.5 \pm 13.1$ & $13 / 37$ \\
\hline
\end{tabular}

Data are presented as total $n$ (patients in Germany/patients in Israel) and mean \pm SD. CBD: chronic beryllium disease. + : positive; -: negative. ${ }^{\#}:$ results are shown as positive (above individual cut-off) or negative proliferation response in BeLPT, only reproducible positive results were accepted as positive. All patients and controls were free of systemic corticosteroid therapy for at least 6 months prior to testing. 


\begin{tabular}{|c|c|c|c|c|}
\hline Individuals & 34 & 7 & 6 & 50 \\
\hline Dental technician/dentist & $13(7 / 6)$ & $1(1 / 0)$ & $4(4 / 0)$ & $10(6 ; 4)$ \\
\hline Engine development/mechanics/ automobile industry & $2(1 / 1)$ & $2(2 / 0)$ & $1(1 / 0)$ & $7(7 / 0)$ \\
\hline Metallurgic factory & $2(1 / 1)$ & & & $4(1 / 3)$ \\
\hline Aircraft production and maintenance & $3(2 / 1)$ & & & $2(2 / 0)$ \\
\hline Nonsparking tools & $1(1 / 0)$ & & $1(1 / 0)$ & $1(1 / 0)$ \\
\hline Radiation shielding & $1(0 / 1)$ & $1(1 / 0)$ & & \\
\hline Military vehicle armour & $2(1 / 1)$ & & & \\
\hline Fluorescent lamps & $2(1 / 1)$ & & & \\
\hline Grinding of optical lenses for precision instruments & & $1(1 / 0)$ & & $1(1 / 0)$ \\
\hline Indirect $^{+}$ & & & & $2(2 / 0)$ \\
\hline
\end{tabular}

Data are presented as total $\mathrm{n}$ (patients in Germany/patients in Israel). CBD: chronic beryllium disease. ${ }^{\#}$ : galvanic industry, ship yards, metal processing; ${ }^{\bullet}$ : additive to glass, ceramics, plastics/catalyst; ${ }^{+}$: i.e. contaminated garments.

\section{RESULTS}

Over a period of $7 \mathrm{yrs}$, in patients for whom the diagnosis of sarcoidosis was suspected or re-evaluated, a potential beryllium exposure was recognised in 84 individuals. Consecutive BeLPT and positive verification of beryllium exposure established the diagnosis of CBD in 34 patients (table 1). In all but six of these cases of CBD, the diagnosis of sarcoidosis was initially made and there was an average delay of 4 yrs (median (range) 3 (0.25-18)) before re-evaluation established the diagnosis of CBD. The mean (range) age of the patients at the time of CBD diagnosis was 43.9(25-80) yrs. In the aforementioned six cases (three in Israel and three in Germany), timely diagnoses of CBD were due to the alertness of primary physicians, occupational physicians or pneumologists.

Although beryllium exposure could be demonstrated in the remaining 50 patients due to reproducibly negative BeLPT findings using blood cells, CBD was excluded and sarcoidosis confirmed. In total, 13 exposed healthy colleagues of the patients could be recruited for BeLPT and seven of them exhibited sensitisation without evidence of CBD. There were 76 healthy individuals without known beryllium exposure who served as controls and all exhibited negative BeLPT results (table 1). Another control cohort consisted of 31 sarcoidosis patients without known beryllium exposure. Beryllium sensitisation was not detected in any of these individuals by BeLPT, which demonstrates its specificity.

The workplaces where beryllium exposure was identified are listed in table 2. In the study on German and Israeli cohorts, dental laboratories were the leading occupational setting of beryllium exposure. However, as already recognised by others, the current authors also observed a wide spectrum of workplaces with beryllium exposure ranging from high-tech industries to technical trades (table 2).

\section{DISCUSSION}

The present differential diagnostic approach demonstrates that cases of CBD may be misclassified as sarcoidosis, which emphasises the necessity of detailed occupational history and eventually BeLPT within the repertoire of diagnostic tools $[3,6$, $7,10]$. A correct diagnosis is of utmost importance since cases of chronic corticosteroid-resistant sarcoidosis may in reality be CBD cases with ongoing exposure, which might prevent response to therapy or spontaneous resolution. The natural courses of CBD and beryllium sensitisation have not yet been analysed in detail. In general, the prognosis is not as good as for sarcoidosis, with an estimated mortality of up to $25 \%$ [6]. However, recent estimates do not exist. Depending on exposure dosage, $2-20 \%$ of exposed individuals become sensitised. Of sensitized individuals, $40-60 \%$ develop granuloma without symptomatic disease and, of these, $50-100 \%$ progress to symptomatic CBD $[5,18,19]$. Progression to clinical disease seems to depend on exposure type [20]. Whether termination of exposure is mandatory to prevent progression is not known, but theoretical scenarios with risk estimation based on occupational epidemiology suggest a benefit from beryllium avoidance [21]. In addition, retrospective studies showed that $\mathrm{CBD}$ improved or even resolved with reduction or termination of exposure [22, 23]. In one of the study patients, the same phenomenon could be observed; CBD came to a spontaneous resolution after a change to a beryllium exposurefree workplace. Thus, after establishing the diagnosis of CBD, avoidance of beryllium is the first recommended therapeutical measure [24].

Occupational history is the mainstay to reveal evidence for possible beryllium exposure, and it is not substitutable by determination of beryllium concentration in tissue or urine. Elevated levels unequivocally demonstrate exposure; however, 
normal values have been observed in clear-cut cases of CBD [25] and even in a fatal case after short-term exposure [26]. In CBD, human leukocyte antigen-DPBv (HLA-DPB) alleles encoding for glutamate at position 69 (Glu69 positive) are overrepresented [27], and genotyping has been suggested as a diagnostic or screening tool. However, the high frequencies of Glu69-positive HLA-DPB alleles of $\sim 33 \%$ in healthy Caucasians, $40 \%$ in African-Americans and up to $59 \%$ in Chinese populations result in low positive predictive values and low specificity for genotyping at the observed disease prevalence [28]. In addition, other polymorphic genes outside the major histocompatibility complex also contribute to susceptibility and disease manifestation [29, 30]. Thus, the presence of Glu69-positive HLA-DPB alleles can only serve as a marker for the risk of sensitisation and not as a diagnostic criterion [2]. Extended genetic testing for supratypic markers, as suggested for HLA-DRPheß47, might give additional information on the risk of beryllium sensitisation [31]; however, a high frequency of this named marker in sarcoidosis $[21,32]$ makes it unlikely that this approach will improve diagnosis of CBD in the near future.

Due to the increased use of beryllium, an increase in the incidence and prevalence of CBD is expected in industries using or manufacturing parts with beryllium alloys or beryllium ceramics and the fact that it has been diagnosed outside the classical beryllium work sector supports this notion $[2,4,5]$. The present binational study demonstrates that relevant beryllium exposure, followed by sensitisation and eventually CBD exists, in a wide spectrum of workplaces in different industries and trades other than the classical workplaces with beryllium exposure known from studies conducted in the USA (table 2). Inhalable particulate matter or fumes from any beryllium-containing material can be generated by high temperatures or by physical processes, such as grating, grinding, scraping, lapping and cutting. Less adherent oxides and hydroxides formed at high temperatures may lead to dust exposure [4], which might also use the skin as a route to cause sensitisation [33]. Moreover, beryllium carried on shoes, clothing and skin from the workplace might cause exposure with consecutive sensitisation for individuals at workplaces without generation of beryllium dust [34] or even at home [10]. Thus, potentially hazardous workplaces due to beryllium exposure are ubiquitous in the current industrialised world and CBD has to be taken into account whenever a disease with noncaseating granulomata is under scrutiny. BeLPT is the sole diagnostic tool to demonstrate sensitisation, which is a prerequisite to make the differential diagnosis as demonstrated in the present 34 cases of CBD. This number might even be an underestimation of CBD in the current cohort, since cases have been reported in which BeLPT with blood cells gave negative results and sensitisation could only be demonstrated by BeLPT with cells of bronchoalveolar lavage [35]. A more frequent use of bronchoalveolar lavage cells might increase sensitivity since a higher frequency of beryllium-specific cells with a higher proliferative capacity is found in lung cells [35, 36]. Unfortunately, the current authors could only make limited use of this option in their CBD cases (data not shown).

In this context, the question arises whether false-positive BeLPT results could cause an overestimation of CBD outside the occupational setting. False-positive results occur at a frequency of $0.00-3.35 \%$ and are identified by the fact that they cannot be confirmed by the mandatory repeated testing. This leads to a positive predictive value for the first abnormal test of 0.253 for CBD and 0.580 for beryllium hypersensitivity [14]. False-negative results have been reported in a range of 24$34 \%$ depending on the algorithms used. For this reason two, or more independent tests are required to exclude suspected beryllium hypersensitivity [14, 37]. In addition, methodological aspects of BeLPT have to be considered [12, 24]. One falsepositive initial test was identified in the present cohort by two consecutive negative BeLPTs, which lead to the diagnosis of sarcoidosis in a beryllium-exposed worker of a foundry. In a cohort of 291 unexposed new hires, three abnormal tests were observed and none of them could be repeated, leading to the conclusion that repeated testing is sufficient to exclude false diagnoses of beryllium hypersensitivity [14].

Only the diagnosis of CBD entails termination of beryllium exposure, which is, although not formally proven, the first recommended step of therapy. Moreover, seven sensitised healthy individuals could be identified who need thorough follow-up by occupational medicine since progression to CBD might take place [20]. Theoretical models suggest that residential exposure due to anthropogenic environmental contamination may lead to an incidental dermal pathway of beryllium uptake, which may eventually cause sensitisation [38]. This leads to the hypothesis that nonoccupational CBD might exist. However, the surveillance study by STANGE et al. [14] does not support this notion.

The current authors are aware that the data presented cannot be used to estimate CBD prevalence within sarcoidosis in Germany or Israel since the institutions are tertiary referral centres in which representative cross-sections of sarcoidosis cohorts are not seen. In addition, some patients have been explicitly sent for performing BeLPT to establish or exclude the suspected diagnosis of CBD. The dimension of underdiagnosing CBD may be estimated by the fact that the 34 cases reported by the current authors have been found within a cohort of 536 sarcoidosis patients referred to the outpatient clinics of the involved institutions during the study period. In addition, a retrospective study of the centre in Israel, not overlapping with the present one, detected three cases in a cohort of 47 re-evaluated sarcoidosis patients [9], indicating a considerable number of misclassified cases. Diagnosing CBD is hampered by the phenomenon of a missing relationship between risk and dose or time of exposure [5]. Minimal exposure over a short period unrecognised by patient or physician may cause disease decades later in life. A triggering co-factor has to be assumed, but is not yet known. Thus, occupational history and eventually BeLPT remain the mainstay of diagnosing CBD.

In conclusion, this test should be used more frequently since, due to its hypersensitive nature, chronic beryllium disease is elicited by minimal beryllium exposures below occupational exposure limits and it cannot be completely eradicated by industrial safety measures [5, 17, 39]. Thus, it will be seen wherever and for as long as beryllium is used. Since a diagnosis of chronic beryllium disease was made in $\sim 40 \%$ (34 out of 84) of "sarcoidosis patients" pre-screened for beryllium exposure, this suggests that the problem might be bigger than expected. 


\section{REFERENCES}

1 Newman LS, Kreiss K, King TE Jr, Seay S, Campbell PA. Pathologic and immunologic alterations in early stages of beryllium disease. Re-examination of disease definition and natural history. Am Rev Respir Dis 1989; 139: 1479-1486.

2 Maier LA. Genetic and exposure risks for chronic beryllium disease. Clin Chest Med 2002; 23: 827-839.

3 Rossman MD, Kreider ME. Is chronic beryllium disease sarcoidosis of known etiology? Sarcoidosis Vasc Diffuse Lung Dis 2003; 20: 104-109.

4 Willis $\mathrm{HH}$, Florig HK. Potential exposures and risks from beryllium-containing products. Risk Anal 2002; 22: 1019-1033.

5 Infante PF, Newman LS. Beryllium exposure and chronic beryllium disease. Lancet 2004; 363: 415-416.

6 Newman LS. Beryllium disease and sarcoidosis: clinical and laboratory links. Sarcoidosis 1995; 12: 7-19.

7 Newman LS, Rose CS, Maier LA. Sarcoidosis. N Engl J Med 1997; 336: 1224-1234.

8 Kent DC, Houk VN, Elliott RC, Sokolowski JW Jr, Baker JH, Sorensen K. The definitive evaluation of sarcoidosis. Am Rev Respir Dis 1970; 101: 721-727.

9 Fireman E, Haimsky E, Noiderfer M, Priel I, Lerman Y. Misdiagnosis of sarcoidosis in patients with chronic beryllium disease. Sarcoidosis Vasc Diffuse Lung Dis 2003; 20: 144-148.

10 Newman LS, Kreiss K. Nonoccupational beryllium disease masquerading as sarcoidosis: identification by blood lymphocyte proliferative response to beryllium. Am Rev Respir Dis 1992; 145: 1212-1214.

11 Lang L. Beryllium: a chronic problem. Environ Health Perspect 1994; 102: 526-531.

12 Mroz MM, Kreiss K, Lezotte DC, Campbell PA, Newman LS. Reexamination of the blood lymphocyte transformation test in the diagnosis of chronic beryllium disease. J Allergy Clin Immunol 1991; 88: 54-60.

13 Stokes RF, Rossman MD. Blood cell proliferation response to beryllium: analysis by receiver-operating characteristics. J Occup Med 1991; 33: 23-28.

14 Stange AW, Furman FJ, Hilmas DE. The beryllium lymphocyte proliferation test: relevant issues in beryllium health surveillance. Am J Ind Med 2004; 46: 453-462.

15 Wemme H, Pfeifer S, Heck R, Müller-Quernheim J. Measurement of lymphocyte proliferation: critical analysis of radioactive and photometric methods. Immunobiology 1992; 185: 78-89.

16 Frome EL, Smith MH, Littlefield LG, Neubert RL, Colyer SP. Statistical methods for the blood beryllium lymphocyte proliferation test. Environ Health Perspect 1996; 104: Suppl. 5, 957-968.

17 Judd NL, Griffith WC, Takaro T, Faustman EM. A model for optimization of biomarker testing frequency to minimize disease and cost: example of beryllium sensitization testing. Risk Anal 2003; 23: 1211-1220.

18 Newman LS, Lloyd J, Daniloff E. The natural history of beryllium sensitization and chronic beryllium disease. Environ Health Perspect 1996; 104S: 937-943.

19 Rossman MD, Stubbs J, Lee CW, Argyris E, Magira E, Monos D. Human leukocyte antigen class II amino acid epitopes: susceptibility and progression markers for beryllium hypersensitivity. Am J Respir Crit Care Med 2002; 165: 788-794.

20 Newman LS, Mroz MM, Balkissoon R, Maier LA. Beryllium sensitization progresses to chronic beryllium disease: a longitudinal study of disease risk. Am J Respir Crit Care Med 2005; 171: 54-60.

21 Bartell SM, Ponce RA, Takaro TK, Zerbe RO, Omenn GS, Faustman EM. Risk estimation and value-of-information analysis for three proposed genetic screening programs for chronic beryllium disease prevention. Risk Anal 2000; 20: 87-99.

22 Sood A, Beckett WS, Cullen MR. Variable response to longterm corticosteroid therapy in chronic beryllium disease. Chest 2004; 126: 2000-2007.

23 Sprince NL, Kanarek DJ, Weber AL, Chamberlin RI, Kazemi H. Reversible respiratory disease in beryllium workers. Am Rev Respir Dis 1978; 117: 1011-1017.

24 Rossman MD. Chronic beryllium disease: diagnosis and management. Environ Health Perspect 1996; 104S: 945-947.

25 Verma DK, Ritchie AC, Shaw ML. Measurement of beryllium in lung tissue of a chronic beryllium disease case and cases with sarcoidosis. Occup Med (Lond) 2003; 53: 223-227.

26 Karkinen-Jaaskelainen M, Maatta K, Pasila M, Saxen L. Pulmonary berylliosis: report on a fatal case. $\mathrm{Br} J$ Dis Chest 1982; 76: 290-297.

27 Richeldi L, Sorrentino R, Saltini C. HLA-DPB1 glutamate 69: a genetic marker of beryllium disease. Science 1993; 262: 242-244.

28 Weston A, Ensey J, Kreiss K, Keshava C, McCanlies E. Racial differences in prevalence of a supratypic HLAgenetic marker immaterial to pre-employment testing for susceptibility to chronic beryllium disease. Am J Ind Med 2002; 41: 457-465.

29 Gaede KI, Amicosante M, Schurmann M, Fireman E, Saltini C, Muller-Quernheim J. Function associated transforming growth factor-beta gene polymorphism in chronic beryllium disease. J Mol Med 2005; 83: 397-405.

30 Amicosante M, Berretta F, Franchi A, et al. HLA-DPunrestricted TNF-alpha release in beryllium-stimulated peripheral blood mononuclear cells. Eur Respir J 2002; 20: 1174-1178.

31 Amicosante $M$, Berretta F, Rossman M, et al. Identification of HLA-DRPhebeta47 as the susceptibility marker of hypersensitivity to beryllium in individuals lacking the berylliosis-associated supratypic marker HLADPGlubeta69. Respir Res 2005; 6: 94.

32 Rossman MD, Thompson B, Frederick M, et al. HLADRB1*1101: a significant risk factor for sarcoidosis in blacks and whites. Am J Hum Genet 2003; 73: 720-735.

33 Tinkle SS, Antonini JM, Rich BA, et al. Skin as a route of exposure and sensitization in chronic beryllium disease. Environ Health Perspect 2003; 111: 1202-1208.

34 Taylor TP, Ding M, Ehler DS, Foreman TM, Kaszuba JP, Sauer NN. Beryllium in the environment: a review. $J$ Environ Sci Health A Tox Hazard Subst Environ Eng 2003; 38: 439-469.

35 Rossman MD, Kern JA, Elias JA, et al. Proliferative response of bronchoalveolar lymphocytes to beryllium: a test for chronic beryllium disease. Ann Intern Med 1988; 108: 687-693. 
36 Pott GB, Palmer BE, Sullivan AK, et al. Frequency of beryllium-specific, TH1-type cytokine-expressing CD4+ T cells in patients with beryllium-induced disease. J Allergy Clin Immunol 2005; 115: 1036-1042.

37 Middleton DC, Lewin MD, Kowalski PJ, Cox SS, Kleinbaum D. The BeLPT: algorithms and implications. Am J Ind Med 2006; 49: 36-44.
38 Deubner DC, Lowney YW, Paustenbach DJ, Warmerdam J. Contribution of incidental exposure pathways to total beryllium exposures. Appl Occup Environ Hyg 2001; 16: 568-578.

39 Paustenbach DJ, Madl AK, Greene JF. Identifying an appropriate occupational exposure limit (OEL) for beryllium: data gaps and current research initiatives. Appl Occup Environ Hyg 2001; 16: 527-538. 